\title{
$\operatorname{arCOS} D E S I G N$
}

\section{Análise da usabilidade de aplicativos rede social para motoristas}

Manuela Quaresma (PUC-Rio, Brasil)

mquaresma@puc-rio.br

Laboratório de Ergodesign e Usabilidade de Interfaces, PUC-Rio

Rua Marquês de São Vicente, 225, Gávea, Rio de Janeiro, RJ

Brasil CEP: 22451-900

Rafael Cirino Gonçalves (PUC-Rio, Brasil)

rafaelcirinogoncalves@gmail.com 


\section{Análise da usabilidade de aplicativos rede social para motoristas}

Resumo: Este artigo traz os resultados de uma análise comparativa (Benchmarking) entre três aplicativos colaborativos para smartphones destinado para uso durante a condução. A análise leva em conta as principais diretrizes de usabilidade para o desenvolvimento de aplicativos para smartphones, juntamente com as de desenvolvimento para dispositivos interativos em automóveis. O estudo teve como objetivo observar e analisar os principais problemas e soluções referentes ao uso destes aplicativos em um contexto de uso tão particular (condução de um automóvel). Os resultados demonstram que, apesar de algumas boas soluções de interface, ainda há soluções potencialmente perigosas para o contexto específico de uso que podem levar a distrações do motorista. Palavras-chave: design de aplicativos , usabilidade, distração do motorista

\section{Usability analysis of social networks applications for drivers}

Abstract: This article presents the results of a comparative analysis (benchmarking) of three collaborative apps for smartphones intended to be used while driving. The analysis takes into account the main usability guidelines for the development of smartphone applications, along with those for the development of interactive devices for vehicles. The study aimed to observe and analyze the main problems and solutions related to the use of these applications in a very particular context of use (driving a vehicle). The results demonstrate that, although there are some good interface solutions, there are still potentially dangerous solutions to the specific context of use that can lead to driver distractions.

Key words: apps design , usability, driver distraction 


\section{Introdução}

Hoje em dia, o Brasil tem mais de 264 milhões de linhas de telefone celular ativas, o que significa uma teledensidade ${ }^{1}$ de aproximadamente 133 linhas de celular para cada 100 habitantes (Anatel, 2013). Porém, do total de usuários de telefone celular brasileiros, apenas $14 \%$ possuem celulares do tipo smartphones, o que corresponde a aproximadamente 27 milhões de usuários de smartphones, de acordo com a pesquisa realizada pela Google em parceria com o Instituto Ipsos (Google \& Ipsos, 2012).

Entretanto, se compararmos o número absoluto de usuários de smartphones brasileiros com o número de outros países da Europa, como a França, por exemplo, com aproximadamente 24 milhões de usuários, correspondendo $38 \%$ de penetração, o Brasil já possui mais unidades de smartphones sendo utilizadas do que muitos países. Além disso, a tendência é de que o uso de smartphones seja muito maior, pois estima-se que até 2015 os smartphones devam representar 57\% do mercado total de celular no Brasil (IDGNow, 2012).

Diferente dos telefones celulares tradicionais, os smartphones são aparelhos de comunicação com tecnologia muito mais próxima a um computador pessoal (PC). Uma das suas principais características são aplicativos que podem ser instalados nele. Os aplicativos são programas (softwares) das mais variadas categorias, que rodam nos sistemas operacionais específicos de cada smartphone. Por exemplo, com o uso da rede de telefonia móvel 3G ou mesmo uma rede Wi-Fi disponíveis em smartphones, é possível acessar a internet através do aparelho para rodar aplicativos de e-mail, redes sociais e mesmo navegar por sites.

Além dos aplicativos e aliada à questão da mobilidade, a geolocalização é outro recurso dos smartphones bastante importante e utilizado, pois é possível através de uma antena GPs localizar o ponto exato onde o smartphone está situado ou mesmo rastrear o caminho percorrido quando ele está em movimento. Com esse recurso, muitos aplicativos foram desenvolvidos para dar suporte à mobilidade das pessoas, possibilitando uma diversidade de novos serviços, como por exemplo, os aplicativos para localização de postos de gasolina próximo à área onde o automóvel/ smartphone está circulando.

Atualmente, existem vários aplicativos de smartphone para serem usados durante a condução de um automóvel, seja para guiar o motorista ao longo do caminho que ele deve percorrer, seja para dar informações sobre o tráfego, seja para avisar sobre os eventos que estão ocorrendo no

1. Índice de distribuição (densidade) de linhas telefônicas numa região. 
trânsito (como acidentes, obras, etc.), e muitos outros serviços. É possível observar nas lojas de aplicativos (virtuais) que, a cada dia, novos aplicativos/serviços vêm sendo desenvolvidos para o uso em automóveis.

Os aplicativos de navegação GPS são sistemas que utilizam uma base de dados com mapas das regiões e a geolocalização para guiar o motorista de um ponto ao outro, indicando cada passo do caminho, tanto por interfaces visuais como por áudio. Além dessa característica básica desse tipo de aplicativo, outros serviços também estão inseridos nesses sistemas, como alerta de radar e informações sobre o trânsito, utilizando a rede de internet. Alguns exemplos de aplicativos populares desse tipo disponíveis no mercado brasileiro são: TomTom Brazil App - sistema de origem holandesa com base de dados e mapas do Brasil; iGo Primo Brazil App - sistema de origem húngara com base de dados e mapas do Brasil; e Sygic GPS Navigation App - sistema de origem eslovaca com base de dados e mapas do Brasil.

Beneficiando-se da possibilidade de comunicação entre as pessoas/usuários de smartphones através da internet, existe outro tipo de aplicativo para uso em automóveis que vem sendo amplamente utilizado a cada dia, conhecidos como aplicativos colaborativos. Eles funcionam como uma "rede social" de motoristas para comunicação durante a condução. Basicamente, todos os aplicativos desse tipo funcionam como alertas de radar ou ocorrências (acidentes, obras, engarrafamento, bloqueios etc.), sinalizados pelos próprios motoristas, que formam uma comunidade específica de um dado aplicativo. Por exemplo, ao conduzir o automóvel numa rua onde há um acidente, o motorista através de inputs no aplicativo alerta a todos os outros motoristas da comunidade de que existe um acidente naquele exato ponto, que é identificado através geolocalização e apresentado para a comunidade pela interface do aplicativo. Alguns exemplos desses aplicativos disponíveis no Brasil e no exterior são: Waze - sistema israelense de alerta comunitário e sistema de navegação GPS disponível em vários países, incluindo o Brasil; Trapster - sistema americano de alerta comunitário disponível em vários países, incluindo o Brasil; e iCoyote - sistema francês de alerta comunitário, disponível em vários países europeus e muito popular na França.

Outro tipo de aplicativo para uso em automóvel muito útil é aquele que transmite unicamente informações sobre trânsito da cidade. Nesses aplicativos não há um guia de rota, apenas as imagens de mapas ou câmeras de monitoramento que apresentam as informações e condições do trânsito, vindas pela internet. Alguns exemplos são: Maplink Trânsito - sistema brasileiro de informação de tráfego em tempo real; Radar G1 - sistema brasileiro de informação de tráfego em tempo real com câmeras de centros de operações das principais cidades brasileiras; e VaiRio - sistema de alertas sobre o tráfego do Rio de Janeiro. 
Esses são apenas alguns exemplos dos aplicativos mais populares no Brasil e no exterior, que estão disponíveis para motoristas. Muitos outros estão disponíveis nas principais lojas de aplicativos (Apple App Store, Google Play, Windows Phone Store, etc.) e muitos ainda devem surgir nessa categoria.

Como pode ser observado nas interfaces da maioria desses aplicativos exemplificados e mesmo em outros aplicativos disponíveis para motoristas, muitas das informações apresentadas nas telas têm um tamanho muito pequeno para serem lidas durante a condução, ainda mais se for considerado que o automóvel está em movimento com trepidação. Não só o tamanho reduzido das informações, mas também a quantidade de informações apresentadas dificulta a leitura e compreensão das mesmas, com telas sobrecarregadas de pictogramas, imagens e textos em alguns casos.

Além disso, outras questões parecem ser problemáticas nas interfaces desses aplicativos, como a demanda visual necessária para a conclusão de tarefas de entrada de dados e a falta de padronização e compatibilidade em relação à expectativa do usuário e aos sistemas operacionais onde os aplicativos rodam (QUARESMA, 2012), assim como o excesso de interações necessárias para fazer o aplicativo funcionar durante a condução. Todos esses problemas podem levar a potenciais distrações do motorista, prejudicando a segurança rodoviária.

\section{A distração do motorista com sistemas de informação e comunicação em automóveis}

De acordo com a NHTSA - National Highway Traffic Safety Administration (NHTSA, 2012), órgão responsável pela segurança no trânsito norte-americano, a distração do motorista pode ser definida como "um tipo específico de desatenção que ocorre quando os motoristas desviam sua atenção da tarefa de dirigir para se concentrar em outra atividade". Esta distração pode ocorrer de diferentes maneiras, de acordo com as seguintes categorias:

- Distração Visual - através de tarefas que exigem que o motorista desvie o olhar da via para obter informação visual (como as interfaces visuais dos aplicativos);

- Distração Manual - através de tarefas que exigem que o motorista retire uma das mãos do volante para manipular algum dispositivo (como a entrada de dados em aplicativos através de telas sensíveis ao toque - touch screens, e botões físico); 
- Distração Cognitiva - através de tarefas que tiram a atenção do motorista para longe da tarefa de dirigir (como tentar compreender uma informação confusa apresentada na interface do aplicativo).

Como a tarefa de dirigir requer do motorista uma especial atenção ao que se passa a sua frente, a distração visual pode ser considerada a que mais ocorre, e consequentemente, a que mais pode causar acidentes. Wang et al. apud Burns \& Landsdown (2000) declararam que 13\% dos acidentes com automóveis nos EUA estão relacionados à distração visual e que parte desta distração pode estar relacionada ao uso de sistemas de informação e comunicação em veículos. Brooks \& Rakotonirainy (2005) ainda colocam que quanto maior for a demanda visual do sistema mais perigosa se torna a condução de um automóvel.

Segundo Orski apud Burns \& Landsdown (2000), empresas desenvolvedoras de equipamentos eletrônicos para automóveis vêm sugerindo como solução para a distração visual a aplicação de interfaces baseadas na fala (comando/ reconhecimento de voz e áudio). Desta maneira, o motorista não teria mais a necessidade de olhar para dentro do veículo e acionar manualmente os controles para concluir a tarefa desejada no equipamento. Porém, neste momento, desconsidera-se o quão isto pode influenciar na carga mental do motorista.

Não só os olhos dos motoristas devem estar atentos à via como também a mente, para evitar tanto a distração visual como também a distração cognitiva. Vários pesquisadores (Harbluk et al., 2000; Burns \& Landsdown, 2000; Lee \& Strayer, 2004) consideram que sistemas baseados na fala não solucionam totalmente o problema da distração com sistemas de informação em automóveis. Dependendo do modelo mental que o motorista faz sobre o sistema, este pode aumentar ainda mais a sua carga cognitiva causando a distração.

Burns (2003) aponta que tanto os dispositivos multifuncionais - equipamentos com diversas funções em um único display e poucos controles, dispositivos tipo plug \& play ou tecnologias portáteis, na maior parte das vezes desconsideram as necessidades, capacidades e limitações dos usuários impedindo a integração eficaz do sistema com o usuário. O autor considera que os dispositivos móveis (como telefones celulares, smartphones e tablets) podem se tornar o maior problema em segurança no trânsito.

Preocupados com o crescente mercado de sistemas de informação e comunicação para automóveis e com o aumento dos riscos de acidentes causados pelas distrações, órgãos governamentais de alguns países (BSI, 1996; EC, 2008; NHTSA, 2012), instituições de pesquisa e associações (stevens e CYNK, 2011; AAM, 2003; JAMA, 2004) elaboraram e publicaram vários guias com diretrizes de projeto para que montadoras e fornecedores pudessem desenvolver seus 
sistemas de maneira adequada à condução de automóveis. Muitos destes guias vem sendo atualizados ao longo dos anos e alguns ainda estão em desenvolvimento conforme pesquisas vendo sendo realizadas com as novas tecnologias. No Brasil, apenas a resolução 242 do CONTRAn (2007) regulamenta a "instalação e utilização de equipamentos geradores de imagens nos veículos automotores", no que se refere ao tipo de informação/imagem a ser apresentada para o motorista. Seu conteúdo é muito simplificado e não fornece nenhuma diretriz de como os dispositivos tanto embarcados quanto os móveis devem ser projetados para evitar distrações do motorista.

\section{A usabilidade em interfaces de dispositivos móveis}

Especialistas em usabilidade e interação humano-computador, como Wroblewski (2011), Gafni (2009), Coursaris e Kim. (2011), Nielsen e Budiu (2012), afirmam que o uso de uma plataforma mobile (dispositivos móveis) se diferencia em diversas questões da plataforma desktop, não só por questões físicas, mas também, por questões conceituais. Desta maneira, não se pode tratar as interfaces para smartphones da mesma forma que são desenvolvidas as interfaces para desktop.

Por se tratarem de aparelhos portáteis, os smartphones não podem ser desvinculados do seu contexto de uso. Para Coursaris e Kim (2012), estes aparelhos têm características específicas devido à sua portabilidade e possibilidade de acesso em qualquer lugar, se encaixando assim nos parâmetros definidos no que Kwahk e Han (2002) chamam de usabilidade contextual.

Podem-se utilizar os aparelhos celulares em praticamente qualquer situação ou local, o que faz com que nem sempre haja tempo ou ambiente adequado para realizar determinada tarefa, sendo então necessária por parte do sistema a adequação ao ambiente e ao contexto em que será utilizado. Clark (2010) e Wroblewski (2011) afirmam que a experiência de se usar um aplicativo é similar com a de se operar algum aparelho com apenas uma mão e um olho enxergando um grande borrão, ou seja, distrações são muito constantes durante a interação, o que faz com que os usuários nem sempre se atentem a detalhes.

Apesar das diferentes possibilidades e cenários de uso, muitos autores (Nielsen e bUdiu, 2012; Fling, 2009; ClARK, 2010, GAFNi 2009, ginsbURG 2010, WROBLEWSKi 2011) afirmam que, devido à dificuldade de interação com a tela pequena, à baixa velocidade de processamento, ao esforço de navegação e à dinamicidade do uso de aparelhos smartphone, as tarefas realizadas dentro de aplicativos devem ser as mais breves, focadas e simples possíveis 
(preferencialmente, apenas uma função por aplicativo). Para os autores mencionados anteriormente, boa parte das questões de usabilidade neste tipo de aparelho estão fortemente relacionadas a limitações de hardware. Tais limitações se impõem durante as etapas de desenvolvimento de um aplicativo, sendo então fatores definitivos para a escolha dos elementos de interface.

Devido à sua capacidade de ser acessado em qualquer lugar, aliado a uma interface gestual em telas sensível ao toque (touch screen), o uso de aplicativos se aproxima muito mais do mundo real do que programas de computador desktop. Quando os smartphones são usados em ambientes externos, uma série de fatores interfere na interação com a interface do mesmo, tanto direta quanto indiretamente. Exemplos comuns são: o ofuscamento da tela devido à luz do sol incidindo sobre a mesma ou a distração devido ao fato do usuário estar dirigindo um automóvel. Tanto Wroblewski (2011), como as diretrizes dos principais OSs (operating systems - sistemas operacionais) de smartphones (Microsoft, 2013; GOOGLE, 2013; APPLE, 2013) afirmam que um bom aplicativo deve estar de acordo com sua interação com o mundo real, levando em consideração seu contexto real de uso visto que os usuários não estão presos a um ambiente reservado para tal.

Wroblewski (2011) ainda afirma que a plataforma móvel dispõe de muitos dispositivos ou funcionalidades não disponíveis na maior parte das vezes na plataforma desktop, entre eles estão o GPS, o acelerômetro e a câmera. Estas ferramentas devem ser utilizadas pelo desenvolvedor para simplificar a entrada de dados e adequar a interação ao contexto mobile. Todos estes dispositivos estão adaptados para a interação móvel, utilizando questões reais, como posicionamento, movimentos e imagens como dados para o sistema.

Devido à suas características específicas quanto à mobilidade e ao hardware, alguns pesquisadores (NAYEBI ET AL. 2012; GAFNI 2009; COURSARIS e KIM. 2011) declaram ainda que métodos de avaliação de interfaces desktop não são adequados para a avaliação de interfaces de dispositivos móveis. Para melhor se avaliar aplicativos, é preciso inserir-se no contexto de uso do mesmo e entender melhor as questões chave para o desenvolvimento para a plataforma mobile.

\section{Metodologia}

Este estudo teve como objetivo a realização de uma análise comparativa (benchmarking) de três aplicativos destinados para utilização durante a condução de automóveis, com base em diretrizes de usabilidade para dispositivos móveis e diretrizes de segurança para o motorista com o uso de sistemas de informação em veículo (IVIs - in-vehicle information systems). 
Os aplicativos escolhidos foram Waze, Trapster, e Wabbers. Estes foram selecionados devido a popularidade e presença nas duas principais lojas de aplicativos (Googe Play e Apple App Store) e suas similaridades por se tratarem de redes sociais dedicadas a motoristas, onde informações relevantes ao trânsito das cidades são compartilhadas pela comunidade, como alertas de radar ou ocorrências (acidentes, obras, engarrafamento, bloqueios etc.). O Waze é a maior das três comunidades de motoristas no Brasil, com elementos de gamefication e a função de navegação GPS. O Trapster é um aplicativo mais focado às notificações de radares e patrulhamento (principalmente em relação a polícia), com diversas outras opções de notificação. Já o Wabbers é a menor das três comunidades, muito similar ao Trapster, porém mais simples com foco nas informações sobre o trânsito. Levando em consideração os requisitos da pesquisa, especificidades do tema e dos objetos estudados, julgou-se necessária a seguinte metodologia:

1. Revisão bibliográfica extensa de livros a respeito de usabilidade e interação humano-computador em interfaces mobile (NIELSEN e BUDIU, 2012; WROBLEWSKI, 2011; CLARK, 2010; NEIL, 2012; FLING, 2009; GINSBURG, 2010), com o intuito de buscar por princípios e diretrizes de design;

2. Revisão bibliográfica de documentos e notificações governamentais, relatório e livros sobre as recomendações para o desenvolvimento de sistemas de informação em veículos - IVIS (AAM, 2003; JAMA, 2004; EC, 2008; STEVENS e CINK, 2011; NHTSA, 2013; HARVEY e STANTON, 2013), também com a finalidade de buscar por normas e diretrizes sobre segurança rodoviária;

3. Levantamento de princípios e diretrizes para o desenvolvimento de aplicativos mobile, a partir de guias de design de interface oferecido pelos principais sistemas operacionais do mercado (APPLE, 2013; GOOGLE, 2013; MICROSOFT, 2013; RIM, 2013);

4. Análise e consolidação de todas as diretrizes emergentes para o design de interfaces mobile e segurança do motorista, utilizando-se uma abordagem bottom-up, como a técnica de Diagrama de Afinidades (BARNUM, 2011);

5. Benchmarking dos aplicativos Waze, Trapster e Wabbers com base nas das diretrizes consolidadas na pesquisa. 


\subsection{Consolidação das diretrizes de usabilidade de aplicativos para smartphones e de segurança do motorista}

Devido ao grande volume de informações coletadas durante a pesquisa, surgiu a necessidade de uma catalogação mais específica, para assim viabilizar uma análise direta entre diretrizes similares provenientes de diferentes fontes como por exemplo, poder comparar o que duas publicações dizem sobre a navegação em menus. Devido à discrepância entre as subcategorias definidas entre as diferentes fontes, aliada à quantidade de dados - muitos deles com as mesmas informações, a técnica escolhida como mais adequada foi o Diagrama de Afinidades, a partir de uma abordagem bottom-up.

A técnica de Diagrama de Afinidades se trata de uma atividade rápida e eficiente para tratamento de um grande volume de informações, com a finalidade básica, conforme definido por Gaffney (1999), de agrupar itens similares. Para Barnum (2011), a técnica é composta por uma série de etapas, as quais preferencialmente devem ser realizadas em grupo, como: 1) coletar informações e escrevê-las em pedaços de papéis ou cartões adesivos (post-its); 2) colocar todos os cartões juntos em um ambiente ou quadro; 3 ) organizar os cartões posicionando juntos os que de alguma forma são relacionados ou similares - preferencialmente sem o diálogo entre a equipe; 4) caso algum cartão apareça em mais de um lugar, ele deve ser copiado; 5) terminada a organização, os membros da equipe devem fornecer um título para cada grupo de cartões; 6) Com os grupos nomeados, eles devem ser postos em uma categorização hierárquica lógica, submetendo um grupo a outro, caso relevante, ou dividindo-os.

Dentro do estudo realizado, foi seguido o modelo de Barnum (2011), com algumas poucas adaptações ao contexto do projeto. Para um melhor entendimento, inicialmente foi feita a separação de cada uma das diretrizes selecionadas dentro dos princípios de usabilidade relacionados na tabela de Quaresma (2010). Uma vez separados em princípios, os cartões foram reagrupados em grupos de similares por questões temáticas - como, por exemplo, navegação, ou aplicação de gestos, e em seguida foi feita uma hierarquização das temáticas, subdividindo os grupos grandes e subordinando os grupos menores. Por fim, houve a consolidação das diretrizes dentro dos respectivos grupos com a união daquelas que apresentavam conteúdo recorrente entre as diferentes fontes.

O processo de consolidação das diretrizes levantadas foi realizado em três etapas. Na primeira, foram agrupadas as diretrizes emergentes da revisão bibliográfica dos livros de usabilidade e interação humano-computador e dos guias de design de interface. Na segunda, foram agrupadas as diretrizes de segurança do motorista para o uso dos IVIs. Na etapa final, os dois agrupamentos foram mesclados, considerando-se a adaptação e a proximidade dos conteúdos. 


\subsection{Definição dos critérios de análise dos aplicativos}

Para a análise comparativa dos aplicativos foi criada uma tabela com todas categorias de diretrizes definidas na consolidação, as quais foram utilizadas como critérios para analisar tela a tela e diálogos de cada um dos aplicativos individualmente. Foram ressaltados tanto os itens que estavam em desacordo com os critérios, assim como os itens positivos em relação aos mesmos, caso determinadas telas e/ou diálogos surpreendessem as expectativas.

Com a análise realizada de cada um dos aplicativos, os três programas foram comparados em série, critério a critério, para que assim pudessem ser tiradas as conclusões sobre o design das interfaces, levando em consideração soluções bem feitas, falhas isoladas e problemas em comum.

\section{Análise das interfaces dos aplicativos}

Com base nos critérios determinados para o benchmarking dos aplicativos, a seguir apresentam-se alguns exemplos das interfaces analisadas de cada categoria de diretrizes de usabilidade e segurança.

\subsection{Contexto}

Esta categoria de diretrizes foca no ambiente e na forma com que as pessoas usam seus smartphones, levando em consideração as questões de concepção e os princípios base sobre mobilidade. No geral, o principal problema encontrado foi referente à interrupção da atenção do motorista em relação a sua tarefa principal (dirigir o automóvel), como no exemplo da caixa de diálogo do Wabbers (figura 1), que interrompe continuamente a atenção do motorista perguntando se está transito ou não no local onde ele está passando, sendo que existem formas de se averiguar tal informação com da verificação da sua velocidade de deslocamento pela conexão com a antena GPS, como é feito no Waze. Nesta categoria, o Waze se destaca devido à possibilidade de interromper determinadas atividades com apenas um clique (figura 2) em um botão posicionado à esquerda da tela, sendo que a mesma pode ser retomada facilmente no momento que for conveniente para o motorista, através de um botão posicionado à esquerda do mapa (figura 3). 


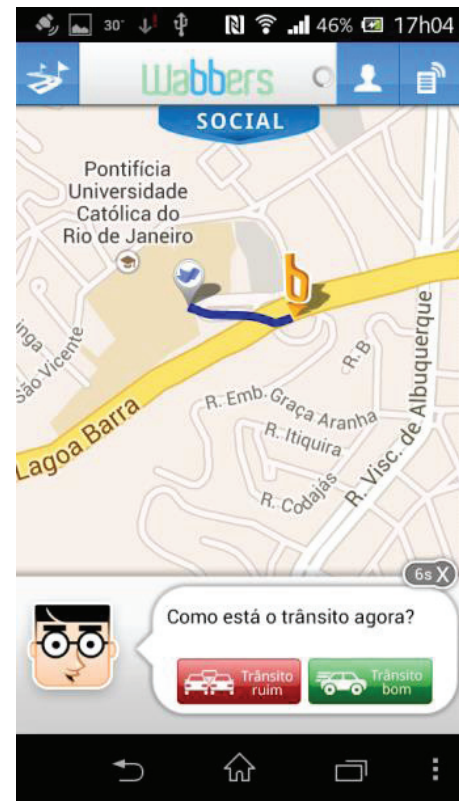

Figura 1. Pergunta recorrente no aplicativo Wabbers durante a condução.

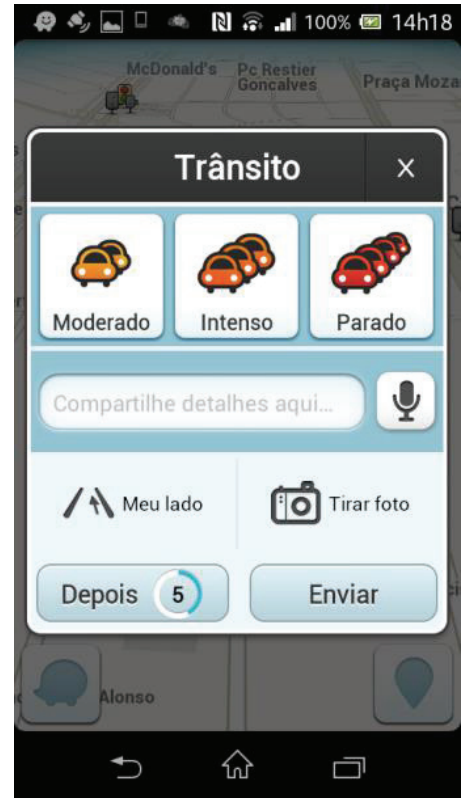

Figura 2. Tela do Waze para notificação de trânsito.

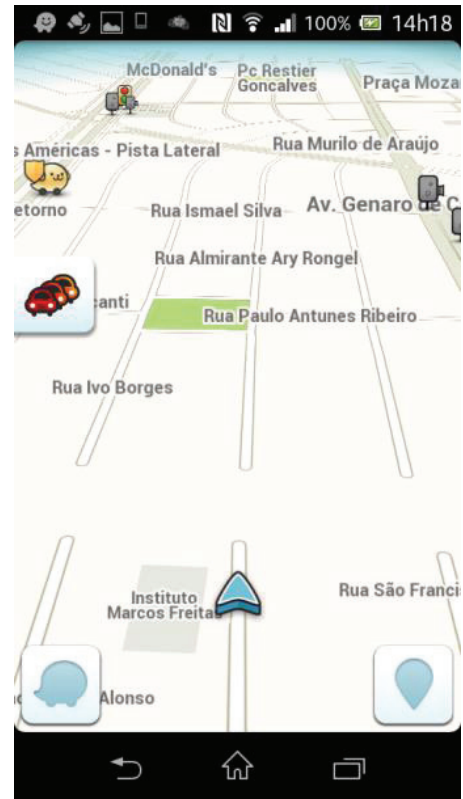

Figura 3. Mapa do Waze com botão de retomar a atividade de notificação.

\subsection{Conteúdo}

A categoria de conteúdo consiste em um grupo de diretrizes voltadas às questões de volume de informação, forma de apresentação e tipos de dados presentes em um aplicativo. Nesta categoria ficou evidente a similaridade estrutural dos três aplicativos. Os problemas encontrados não apresentaram um padrão recorrente entre eles, o que leva a crer que foram casos isolados. O primeiro problema encontrado foi no aplicativo Wabbers, que quando comparado com seus competidores apresenta de um excesso de elementos gráficos de interface na tela inicial do mapa, ocupando espaço valioso da tela que acaba por ocultar informações importantes do mapa (figura 4) - fato quer se torna mais aparente quando as informações são exibidas em formato paisagem (landscape) (figura 5). 


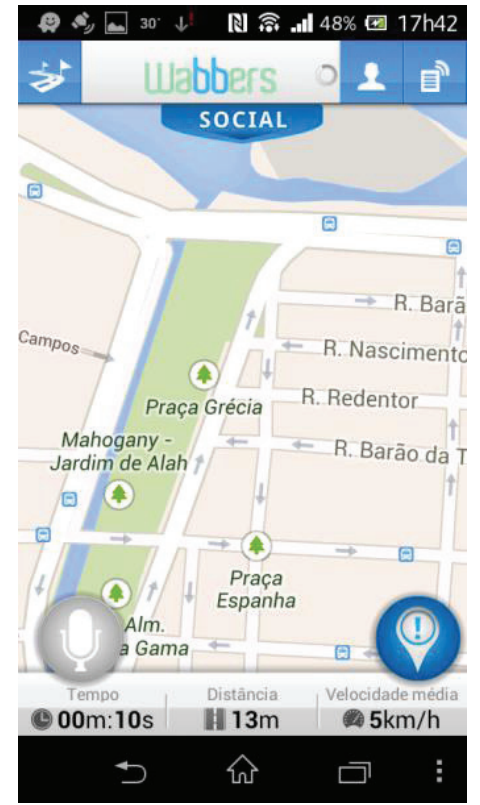

Figura 4 .Tela inicial do Wabbers modo retrato (portrait).

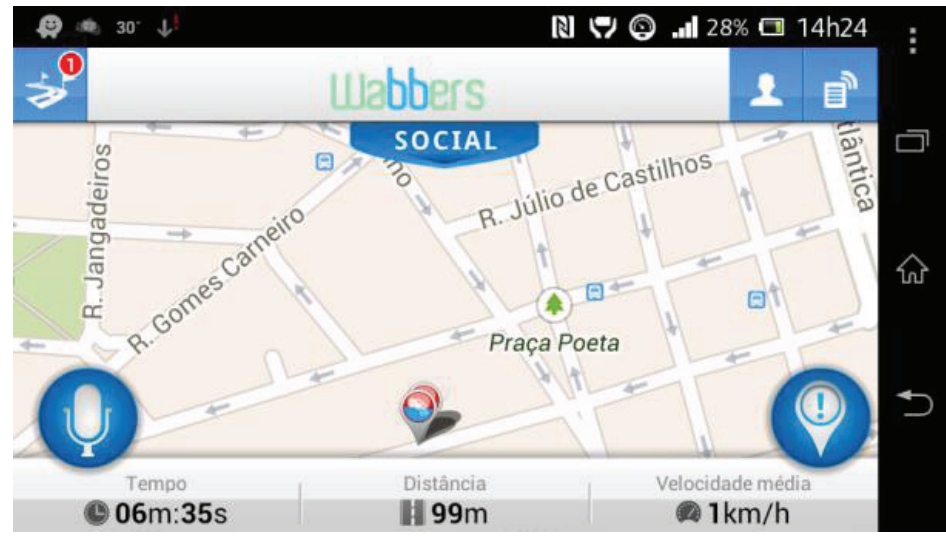

Figura 5. Tela inicial do Wabbers em modo paisagem (landscape)

O segundo ponto onde foram encontrados problemas nas interfaces foi referente ao excesso de texto dentro dos aplicativos Waze e Wabbers. No caso do Waze, o excesso de texto foi encontrado em uma série de menus pop-up como por exemplo a tela de reportar erro no mapa (figura 6) - exigindo que o usuário realize um scroll para ler todas as informações. Em outros casos, foram encontrados menus com textos excessivos e ilegíveis durante a condução devido ao tamanho da fonte (figura 7), aumentando assim a possibilidade de distração durante seu uso, visto que próximo ao texto se encontravam diversos elementos de interação. Já o Wabbers apresentou uma quantidade excessiva de texto, apresentadas em caixas de diálogo pequenas (figura 8). O texto deveria ser curto e objetivo e acabou perdendo o foco, devido ao seu tamanho, se tornando ilegível durante a condução. O Trapster também apresenta rótulos muito pequenos para a legibilidade durante a condução em seu menu de notificação de ocorrências (figura 13). 


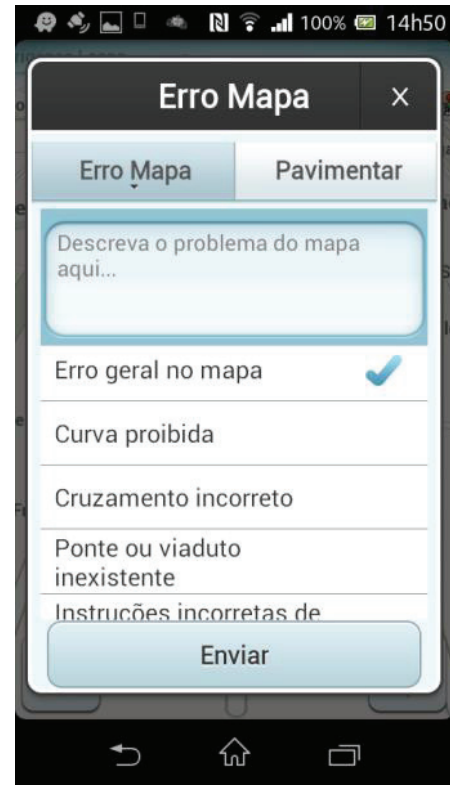

Figura 6. Menu pop-up do Waze de notificar erro no mapa.

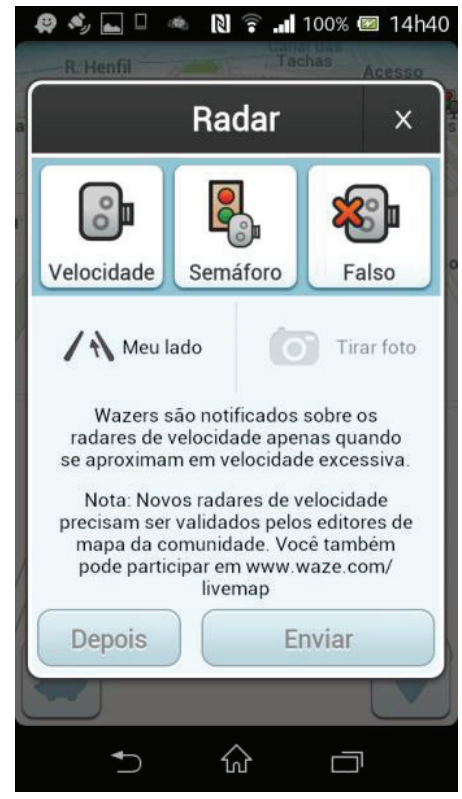

Figura 7. Menu pop-up do Waze responsável por notificar radares.

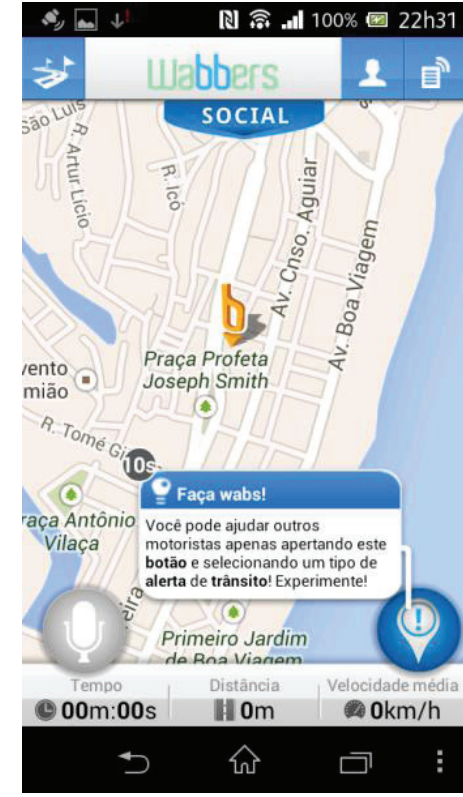

Figura 8. Notificação de mensagem do Wabbers.

\subsection{Arquitetura de Informação}

Este grupo de diretrizes tem seu conteúdo voltado a questões de estrutura geral dos aplicativos, seguindo os sistemas principais da arquitetura da informação - navegação, rotulação, organização e busca. Dentro dessa categoria, muitos pontos em comum entre os três aplicativos encontram-se com problemas. Os três apresentam um grande número de opções (figuras 9, 10 e 11) para configuração de seu aplicativo - nem todas relevantes para o contexto da condução, exibindo uma longa lista de elementos, que podem prejudicar a interação do usuário. Neste ponto o Trapster apresenta uma melhor solução, ao subdividir suas configurações em um pequeno menu em formato de lista. 


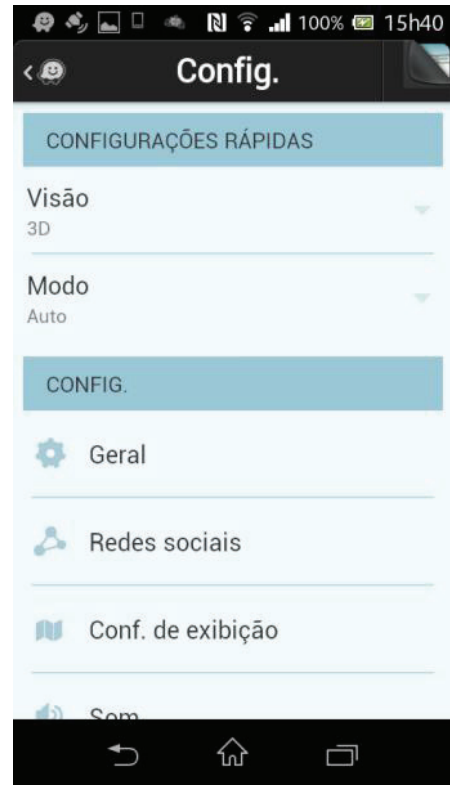

Figura 9.Tela de configurações do Waze.

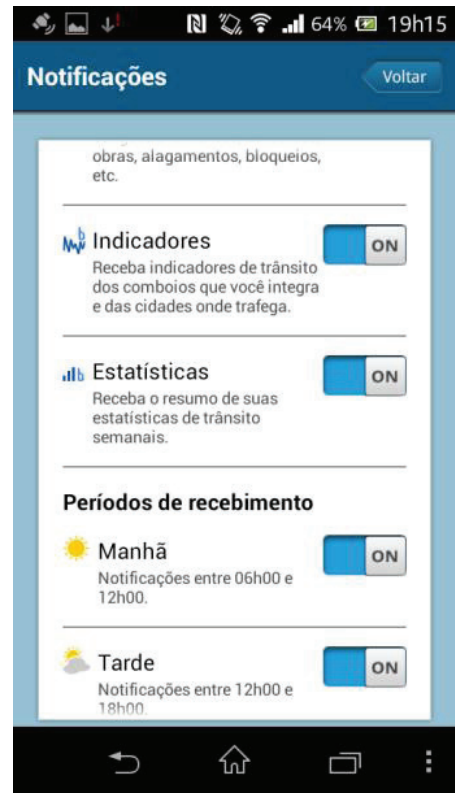

Figura 10. Tela de configuração de notificações do Wabbers.

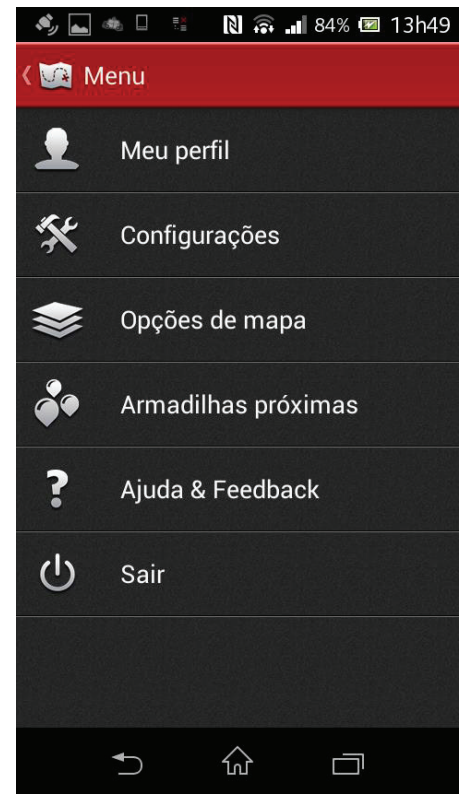

Figura 11. Tela de menu do Trapster.

Um segundo problema em comum aos três é o fato de que os menus de notificação de alerta de ocorrências (apresentados no modelo de menus de grade) apresentam um grande número de opções, podendo ocultar opções que poderiam ser importantes de acordo com o contexto/momento (figuras 12, 13 e 14). O único dos três aplicativos que apresenta todas as suas opções sem a necessidade de scroll é o Wabbers (figura 14), porém o mesmo apresenta ícones e rótulos menores, com pouco contraste, prejudicando a legibilidade. Este é um típico problema que ocorre quando é necessário apresentar múltiplas opções em telas pequenas. Uma solução mais compatível com o contexto da condução é a redução da quantidade de opções para aquelas mais frequentes de uso e o agrupamento das menos frequentes, como é feito com alguns sistemas de navegação GPS para as categorias de POI (pontos de interesse) (QUARESMA, 2010). 


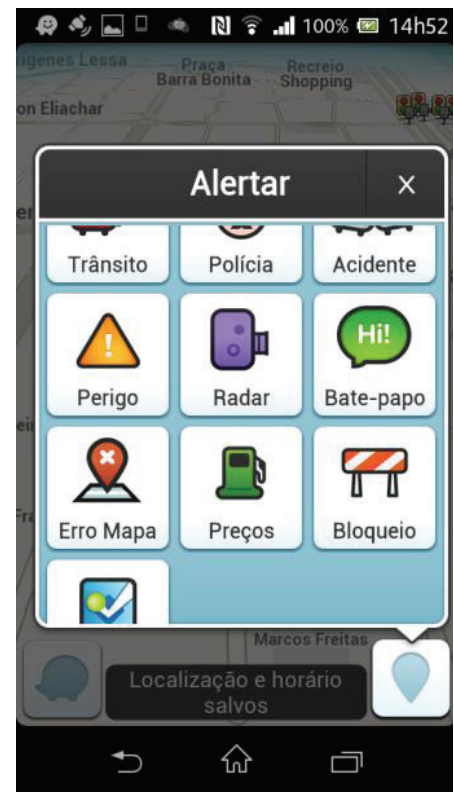

Figura 12. Tela de notificação de ocorrências do Waze.

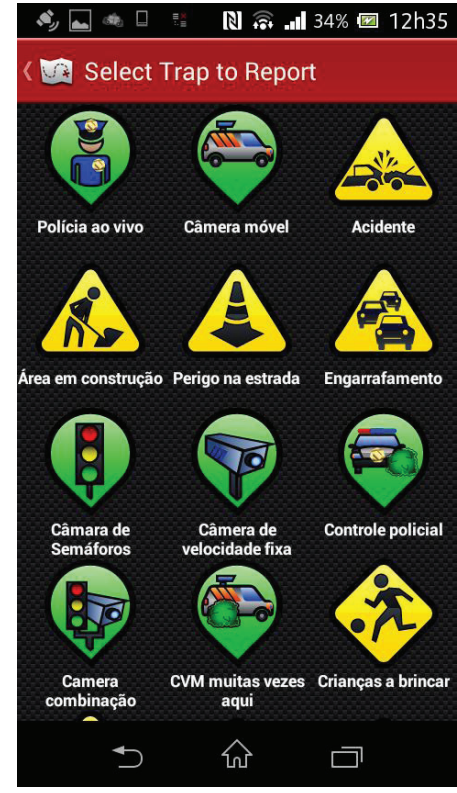

Figura 13. Tela de notificação de ocorrências do Trapster.

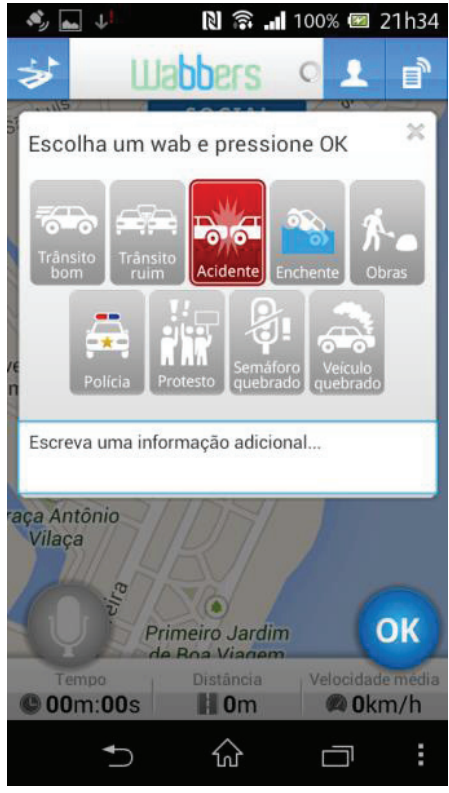

Figura 14. Tela de notificação de ocorrências do Wabbers.

Em suas versões para Android, os três aplicativos utilizam botões de retroceder em suas interfaces (figuras 15, 16 e 17), desprezando o botão de sistema (back button) já presente no aparelho - no caso do Wabbers (figura17), o aplicativo impede o usuário de usar o botão de sistema em seus pop-ups. Um outro ponto crucial a ser destacado é que dos três aplicativos analisados, apenas o Waze (figura 15) apresenta um atalho de qualquer ponto de sua hierarquia para o mapa, função essencial dentro deste tipo de aplicativo, visto que sua ausência dificulta o motorista a retornar para a sua tarefa principal com o aplicativo caso queira abortar alguma tarefa secundária por algum motivo, como uma emergência. 


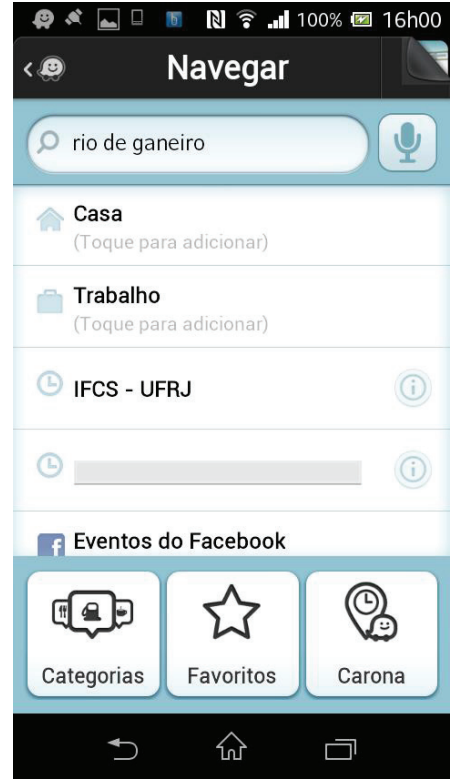

Figura 15. Tela de navegar do Waze.

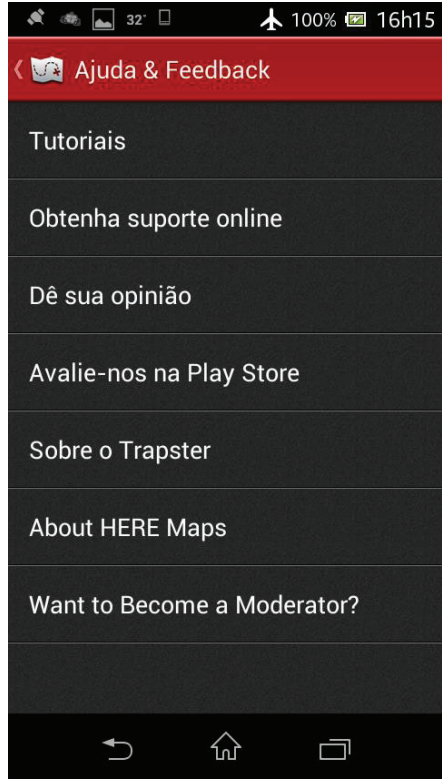

Figura 16. Menu de ajuda do Trapster.

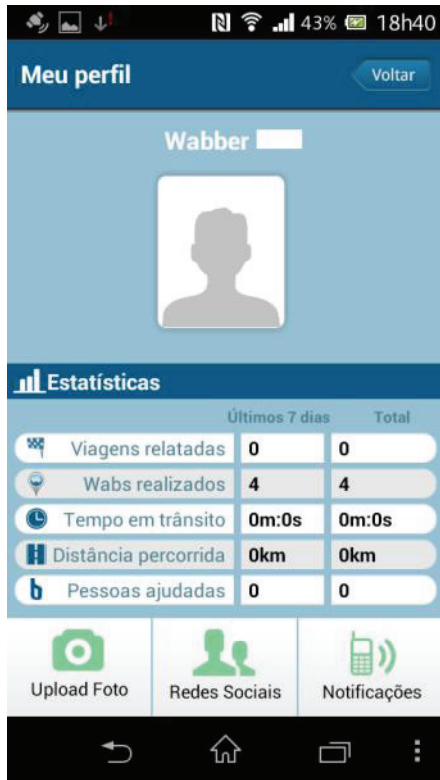

Figura 17. Menu de Perfil do Wabbers.

Individualmente, os aplicativos também apresentam pontos que devem ser considerados em relação a esta categoria, como por exemplo, todos os três permitem a utilização imediata do aplicativo assim que inicializado, sem a necessidade de login, porém o Trapster exibe anúncios em relação a sua conectividade com outras redes sociais, assim que o aplicativo é aberto (figura 18), se tornando um possível incomodo para os usuários. Outro exemplo pode ser observado nos elementos visuais no mapa do Waze, alguns deles são navegáveis e outros não (figura 19), porém não há nenhum indicativo da diferença entre os dois, fato que não é encontrado nos outros dois aplicativos, onde todos os elementos apresentados no mapa são interativos. Um erro encontrado de gênero similar no Waze, foi no menu de notificação, pois ele oferece a opção de indicar de que lado da via a notificação está sendo feita, porém a interface não deixa claro que o elemento responsável pela função é realmente um botão (figura 20). 


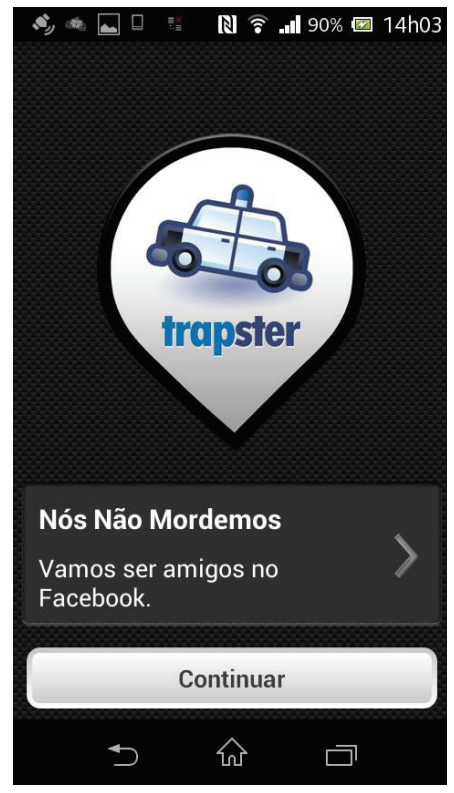

Figura 18. Tela de convite a conexão com o FaceBook do Trapster.

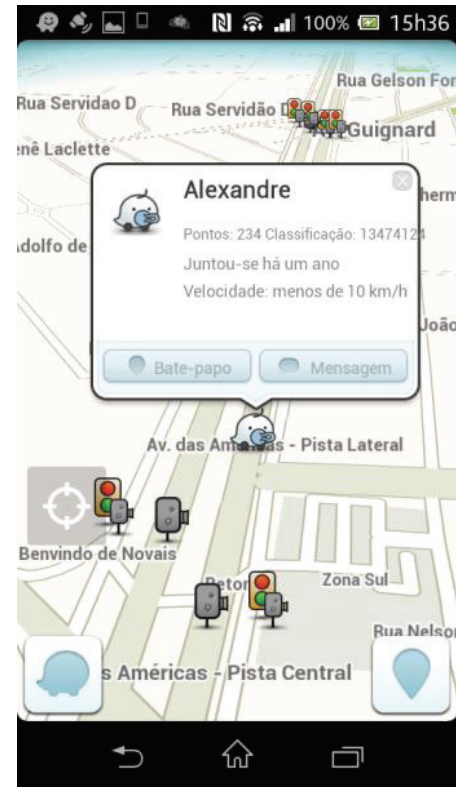

Figura 19. Pop-up de detalhe sobre usuário no Waze.

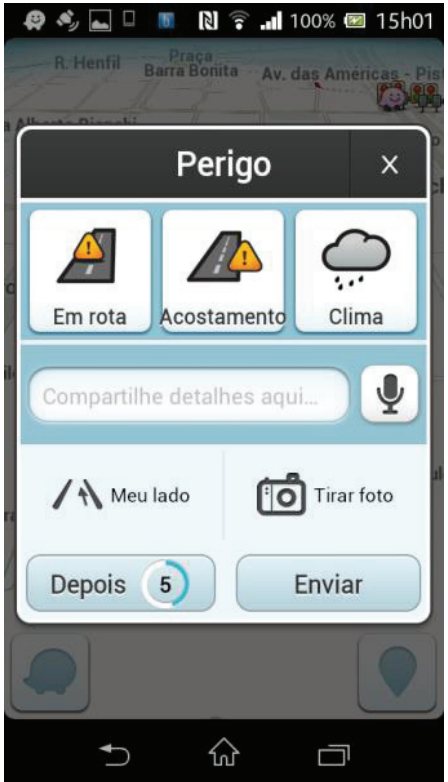

Figura 20. Tela de notificação de perigo do Waze.

Ainda sobre nomenclatura e rotulação, o Trapster apresenta uma inconsistência na língua onde suas mensagens são apresentadas para o usuário (figura 13) ora em inglês ora em português. Na mesma categoria, o Trapster apresenta erros de grafia na palavra câmera - escrevendo "câmera" ou "câmara" ou "camera" ou "CRV" (figura 13). Sobre o formato dos ícones deste aplicativo, não há uma ordem lógica em que eles são dispostos no menu de notificação de ocorrências (figura 13), podendo deixar o usuário perdido na interface.

\subsection{Layout de Tela}

A categoria Layout de Tela agrega diretrizes relacionadas à forma com a qual lidamos com a interface gráfica dos aplicativos. Dentro desta categoria, os três aplicativos apresentaram diferenças entre si. Aliadas a estas diferenças foram encontrados vários pontos negativos. Um deles foi o fato do Trapster não adaptar os elementos de interface dinamicamente a partir da ocultação daquilo que não está sendo utilizado no momento (figura 21) - mecânica utilizada pelos seus concorrentes (figura 22), como botões em transparência que desaparecem caso não sejam utilizados. Também, as ferramentas contextuais do Wabbers são muito pequenas e próximas entre si (figura 23), tornando propícia a ocorrência de erros, ao contrário do Trapster, que apresenta todos os elementos de interação em tamanho adequado e leva em consideração seu uso dentro de veículos em movimento. 


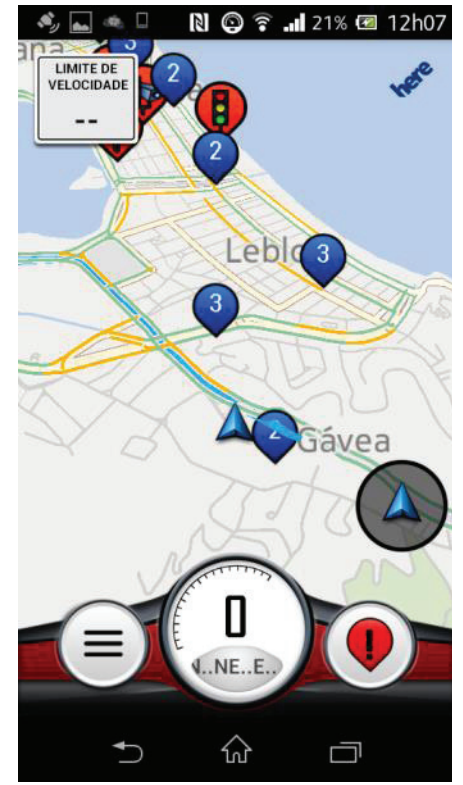

Figura 21. Tela inicial do Trapster.

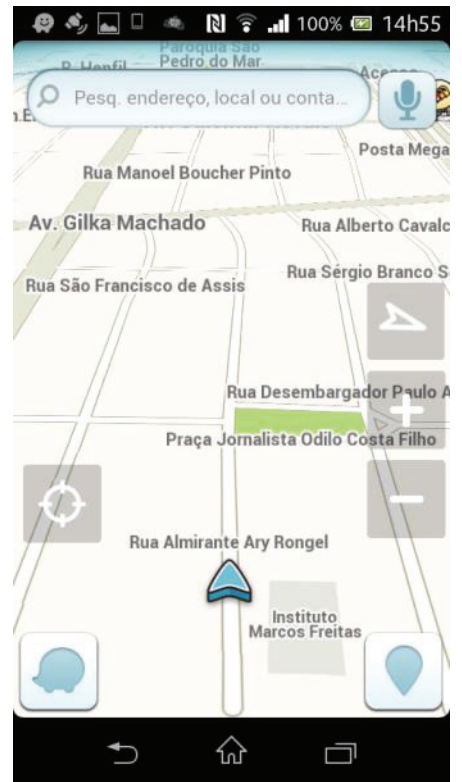

Figura 22. Tela inicial do Waze com elementos contextuais de navegação.

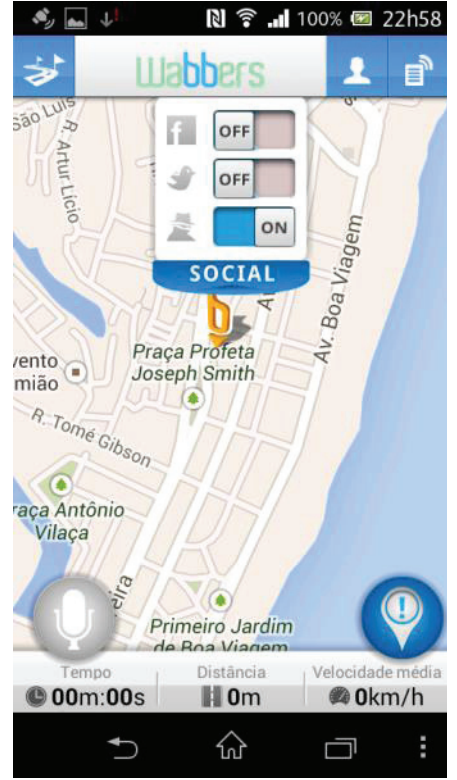

Figura 23. Tela inicial do Wabbers com o pop-up do menu de redes sociais.

Em relação aos elementos gráficos desnecessários, o Wabbers apresenta uma grande barra no topo da tela (figura 8), contendo apenas o nome do aplicativo, ocupando espaço valioso que poderia estar exibindo informações do mapa. Tal problema se torna evidente quando comparado com o Waze e o Trapster (figuras 22 e 21) que apresentam uma interface limpa e clara. Ainda sobre o Wabbers, aplicativos desenhados para serem utilizados dentro de automóveis geralmente possuem alguma forma de ajustar as cores de sua interface de acordo com o horário em que está sendo utilizado (modo dia/noite), porém o Wabbers não possui tal função, podendo prejudicar o motorista ofuscando sua visão a noite.

\subsection{Gráficos}

Esta categoria é focada em recomendações para uso de gráficos (do tipo com eixos x e y ou escalas). Este tipo de aplicativo não utiliza-se de muitos gráficos, e os poucos utilizados apresentam-se de forma razoável para o contexto em que são visualizados (figura 24). 


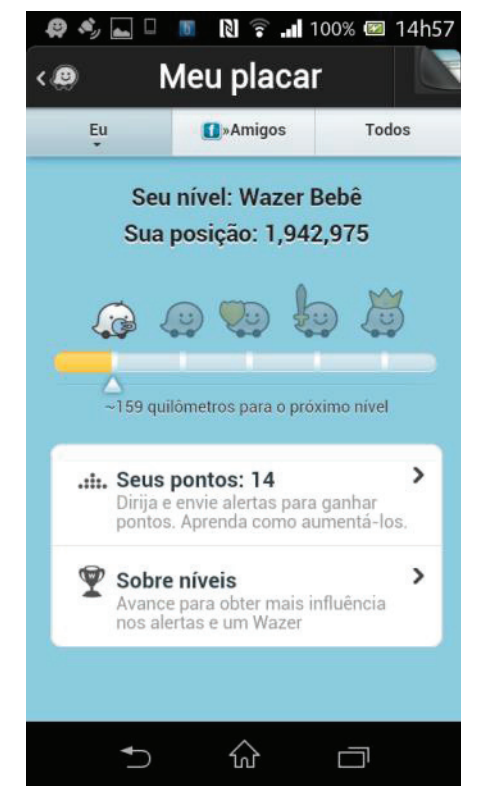

Figura 24. Gráfico de evolução do Waze.

\subsection{Formulários}

Esta categoria responsável por apresentar as diretrizes de usabilidades referentes ao uso de formulários dentro da plataforma mobile. Nesta questão, os três aplicativos apresentaram boas soluções levando em consideração o contexto de uso. Esta eficiência fica clara ao se observar os pequenos e breves formulários para se notificar um incidente no mapa (figura 14) - muitos deles necessitando de apenas um botão. Outro ponto que deve ser ressaltado é o fato de cadastros serem prescindíveis para a interação com o mapa - até mesmo quando o cadastro é feito, os sistemas ajudam o seu preenchimento dando exemplos em seus campos de preenchimento (figura 25) ou permitindo a entrada a partir da conta do Facebook ou Gmail (figura 26) presente no aparelho. 


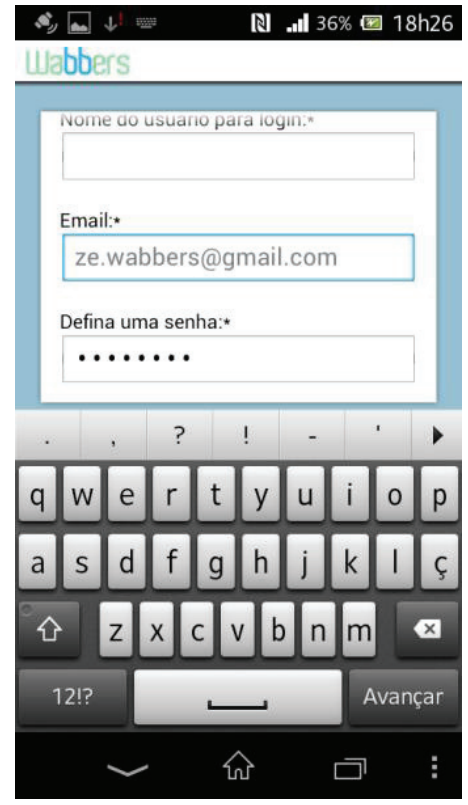

Figura 25. Tela de cadastro do Wabbers.

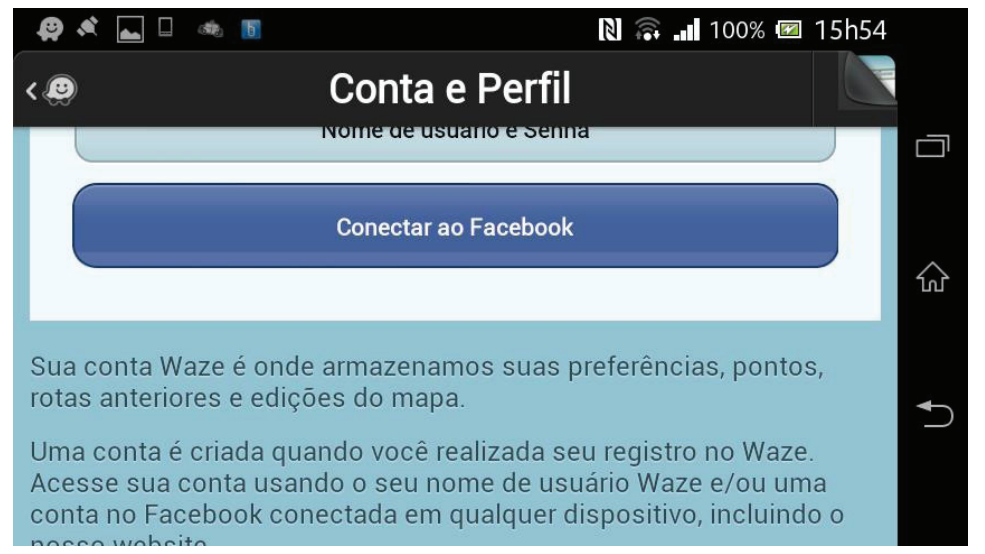

Figura 26. Tela de opção de cadastro no Waze via Facebook.

\subsection{Diálogo}

As diretrizes de Diálogo são referentes à forma de comunicação expressa por parte do sistema com o usuário. Levando em consideração a quantidade de texto exibido, o Wabbers e o Waze (figuras 9 e 10) apresentam textos muito longos e frequentes ao longo de sua interface, com informações desnecessárias e pouco coerentes em relação ao contexto da condução. Já o Trapster, com suas mensagens bem claras e sucintas, praticamente não apresenta mensagens textuais (figura 11). Em relação à nomenclatura, os três se apropriam do seus nomes como alegorias para nomear os seus elementos de perfil e notificação. Um exemplo claro disso é o usuário do Waze ser chamado de Wazer ou as notificações do Wabbers serem chamadas de Wabs.

Em relação a questões de ajuda ao usuário, todos eles oferecem helps completos de diferentes maneiras, o Wabbers (figura 27) apresenta um ajudante de navegação presente e constante, porém todos os seus helps são textuais. Os helps do Trapster são apresentados assim que o aplicativo é inicializado pela primeira vez com mensagens claras e explicativas (figura 28). 


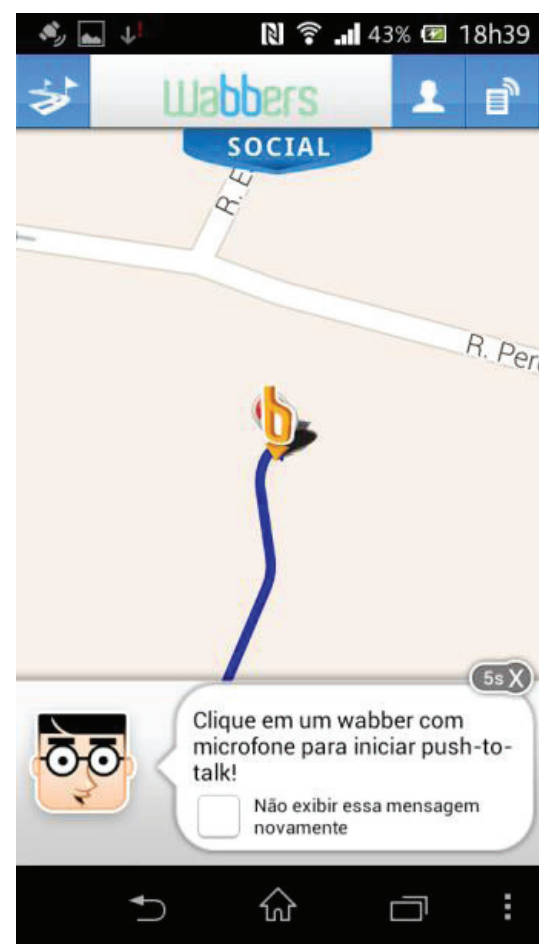

Figura 27. Tela inicial do Wabbers com help textual.

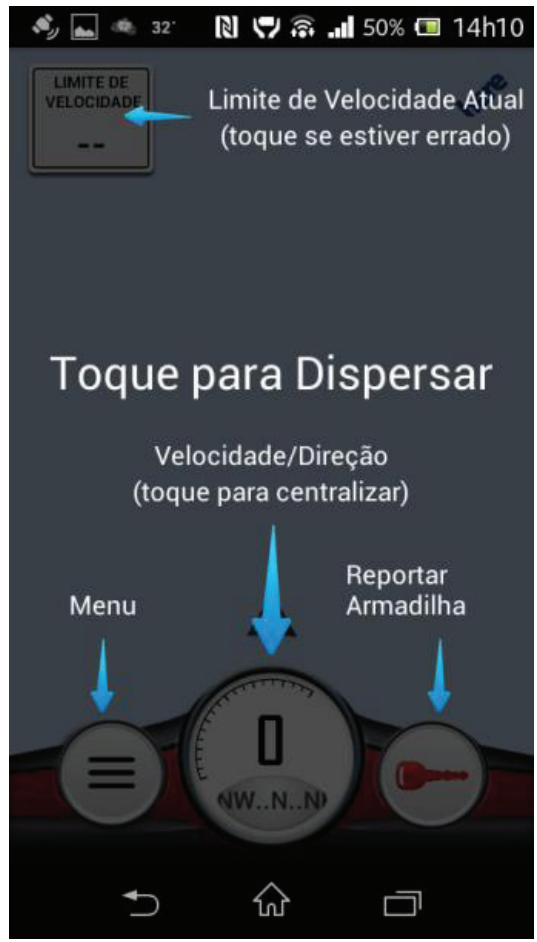

Figura 28. Tela de help do Trapster.

No que se refere a feedback, o erro mais gritante foi encontrado no Waze, o qual não oferece nenhum feedback que alguma imagem está sendo carregada ao mesmo tempo em que a tela está sendo exibida, podendo ser facilmente confundido com um erro de carregamento.

\subsection{Métodos de Entrada}

Esta categoria tem em seu conteúdo diretrizes relacionadas ao uso de ferramentas para a entrada de dados, sejam teclados, gestos ou sensores diversos. Nela, os três aplicativos apresentaram no geral soluções razoáveis, permitindo a manipulação direta das informações presentes no mapa com o dedo e se utilizando de métodos de entrada alternativos para substituir a digitação, como o reconhecimento de voz. Apesar dessas soluções, o aplicativo Waze tem um ponto muito mal resolvido em relação a digitação de dados do endereço de destino. Apesar do aplicativo apresentar corretor automático de texto (figuras 29 e 30), ele não usa nenhum tipo de filtro ou texto preditivo na busca por rotas (figura 31) - função muito comum em sistemas de navegação GPS, dificultando a entrada de dados durante a condução e possibilitando erros em sua busca. 


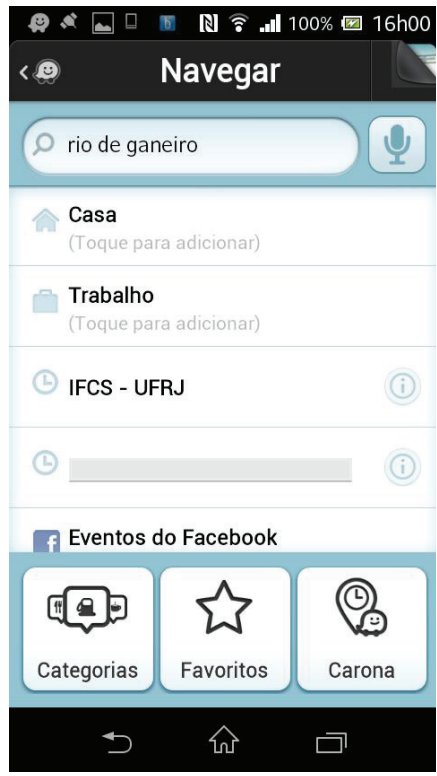

Figura 29. Tela de navegar do Waze com erro de digitação.

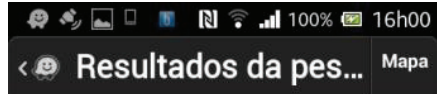

Rio de Janeiro

Rio de Janeiro, Brazil

$29.7 \mathrm{Km}$ distante

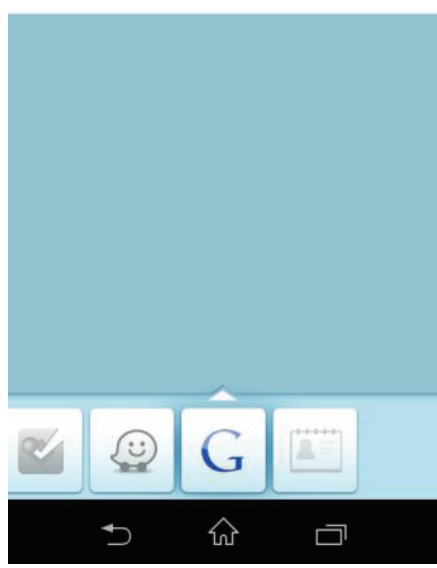

Figura 30. Tela de resultados de rota do Waze.

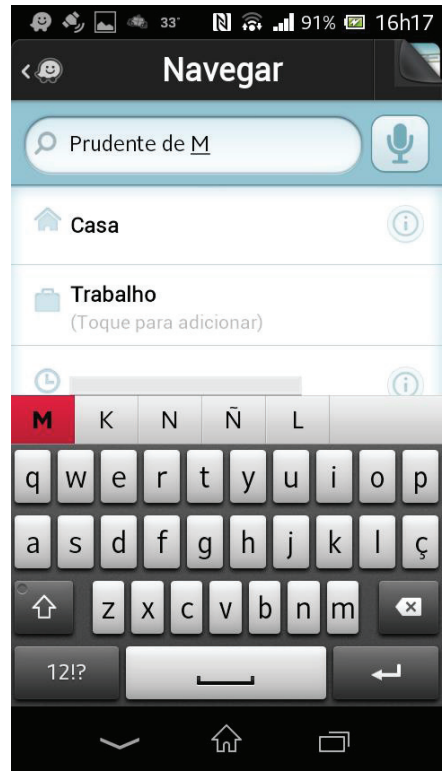

Figura 31. Tela de configuração de rota do Waze com texto incompleto.

\subsection{Funções do Sistema}

Por fim, a categoria Funções do Sistema agrupa diretrizes referentes à ferramentas e questões específicas do contexto mobile, como o autosave ou os dispositivos integrados - GPS, câmera e acelerômetro.

Com muitos pontos bem resolvidos, como o uso de autosave em todas as preferências e comportamentos do usuário, o único ponto negativo relevante encontrado nesta categoria foi a questão das configurações extensa, a qual apenas o Trapster resolve de maneira satisfatória com um menu de listas. Outros fatores que valem ser ressaltados é a possibilidade de compartilhamento de informações via outras redes sociais e a utilização de métodos de entrada alternativos, explorando todas as possibilidades de hardware, como por exemplo o uso da câmera fotográfica para confirmar as notificações de ocorrência para a comunidade.

\section{Considerações finais}

É fato que o mercado de smartphones vem crescendo aceleradamente, e este crescimento vem acompanhado de um avanço das tecnologias de entrada de dados e geolocalização inerentes aos aparelhos. Tais avanços propiciam a criação de aplicativos voltados para a utilização em automóveis, que podem tanto ajudar 
na condução quanto distrair o motorista, caso não sejam projetados levando em conta o contexto de uso e os princípios de design referentes ao mesmo.

Esta pesquisa teve como objetivo a realização de um benchmarking entre três aplicativos que funcionam como redes sociais para motoristas - Waze, Trapster e Wabbers - levando em consideração as principais diretrizes de usabilidade para smartphones juntamente com as de segurança no uso de IVIs. O resultado da pesquisa foi uma análise comparativa entre os três aplicativos, levantando quais as melhores soluções para os diferentes problemas encontrados em cada um deles. Chegou-se também à conclusão de que a quantidade de usuários presentes na comunidade deste tipo de aplicativo influencia diretamente na qualidade do conteúdo do mesmo, visto que o conteúdo principal neste tipo de aplicativo é conseguido a partir de notificações do usuário em relação aos diversos fatores relativos ao trânsito, logo uma comunidade pequena pode não gerar a constância necessária para a atualização e verificação das informações trazendo um conteúdo defasado.

Esta pesquisa faz parte de um estudo continuado sobre usabilidade de aplicativos de smartphones desenvolvidos para o uso em automóveis. Com seus desdobramentos pretende-se fazer estudos similares com outras categorias de aplicativos, no intuito de averiguar os achados deste estudo e chegar a um consenso sobre as recomendações de usabilidade para este tipo de aplicativo e interação (motorista-smartphone).

\section{Referências bibliográficas}

Agência Nacional de Telecomunicações (Brasil). Relatório de Acessos Móveis em Operação e Densidade por UF. Disponível em: http://www.anatel.gov. br/. Data de acesso: 19 de abril de 2013.

APPLE. iOS Human Interface Guidelines. 2013. Disponível em: < https://developer.apple.com/library/ios/documentation/UserExperience/ Conceptual/MobileHIG/index.html >. Acesso em: 03 set. 2013.

BARNUM, C. M. Usability Testing Essentials: Ready, Set...Test! Burlington: Morgan Kaufmann, 2011. 408 p. ISBN 012375092X.

BROOKS, Chad; RAKOTONIRAINY, Andry. In-Vehicle Tecnologies, Advanced Driver Assistance Systems and Driver Distraction: Research challenges. In: Proceeding of International Conference on Driver Distraction. Sydney, 2005. 
BURNS, P.; LANSDOWN, T.. E-distraction: the challenges for safe and usable internet services in vehicle. In: Proceedings of NHTSA Driver Distraction Internet Forum. Rockville: Westat, 2000. http://www-nrd.nhtsa.dot.gov/departments/nrd-13/driver-distraction/Welcome.htm. Acesso em: 12 jun 2005.

BURNS, Peter (2003). Strategies for reducing driver distraction from in-vehicle telematics devices: a discussion document. http://www.tc.gc.ca/ roadsafety/tp/tp14133/menu.htm. Acesso em: 2 jun 2006.

CLARK, J. Tapworthy: Designing Great iPhone Apps. Sebastopol: O'Reilly Media, 2010. 322 p. ISBN 1449381650.

COURSARIS, C. K.; KIM, D. J. A Meta-Analytical Review of Empirical Mobile Usability Studies. Journal of Usability Studies, v. 6, n. 3, p. 117-171, 2011.

EUROPEAN COMMUNITIES. Recommendations on safe and efficient in-vehicle information and communication systems: update of European statement of principles on human machine interface. Brussels: European Union (Official Journal 2008/653/EC), 2008.

FARBER, E.; FOLEY, J.; SCOTT, S. Visual attention design limits for ITS in-vehicle systems: The Society of Automotive Engineers standard for limiting visual distraction while driving. Washington: Transportation Research Board Annual General Meeting, 2000.

FLING, B. Mobile Design and Development: Practical Concepts and Techniques for Creating Mobile Sites and Web Apps (Animal Guide). Sebastopol: O'Reilly Media, 2009. 336 p. ISBN 0596155441.

FOLEY, James P. Lessons Learned from the Development of J2364. In: 2005 SAE World Congress. Detroit: SAE International, 2005. 2005-01-1847.

GAFFNEY, G. Affinity Diagramming. 1999. Disponível em: < http://infodesign.com.au/usabilityresources/affinitydiagramming/ >. Acesso em: 02 out. 2013.

GAFNI, R. Usability Issues for Wireless Devices. Issues in Informing Science and Information Technology (IISIT), v. 6, n. 1, p. 755-769, 2009. 
GINSBURG, S. Designing the iPhone User Experience: A User-Centered Approach to Sketching and Prototyping iPhone Apps. Boston: AddisonWesley Professional, 2010. 336 p. ISBN 0321699432.

GOOGLE. Android Design Guidelines. 2013. Disponível em: < http://developer.Android.com/design/index.html >. Acesso em: 03 set. 2013.

GOOGLE; IPSOS. Our mobile planet. Disponível em: http://www.thinkwithgoogle.com/mobileplanet/en/ . Data de acesso: 15 de novembro de 2012.

HARVEY, Catherine; STANTON, Neville. Usability evaluation for in-vehicle systems. Boca Raton: CRC Press, 2013.

IDGNOW. Venda de smartphones no Brasil sobe quase $80 \%$ no primeiro semestre. Disponível em: http://idgnow.uol.com.br/mobilidade/ 2012/09/13/ venda-de-smartphones-no-brasil-sobe-quase-80-no-primeiro-semestre/. Data de acesso: 15 de novembro de 2012.

JAPAN AUTOMobile MANUFECTURERS ASSOCIANTION - JAMA. Guidelines for in-vehicle display systems. Tokyo: JAMA, 2004.

KWAHK, J. Y.; HAN, S. H. A methodology for evaluating the usability of audiovisual consumer electronic products. Applied Ergonomics, v. 33, n. 5, p. 419-431, Sep 2002. ISSN 0003-6870.

LEE, John D.; STRAYER, David L. Preface to special section on driver distraction. Human Factors, Santa Monica, v. 46, n. 4, p. 583-586, 2004.

MICROSOFT. Design Library for Windows Phone. 2013. Disponível em: < http://msdn.microsoft.com/en-us/library/windowsphone/design/ hh202915(v=vs.105).aspx >. Acesso em: 03 set. 2013.

MOTION, R. I. Blackberry Key Principles. 2013. Disponível em: < https:// developer.blackberry.com/devzone/design/bb10/key_principles.html >. Acesso em: 03 set. 2013.

National Highway Traffic Safety Administration. Visual-Manual NHTSA Driver Distraction Guidelines for In-Vehicle Electronic Devices. Vol. 77 No. 37, 2012. 
NAYEBI, F. et al. The State of Art of Mobile Application Usability Evaluation. 2012 25th IEEE Canadian Conference on Electrical \& Computer Engineering (Ccece): 4 p. 2012.

NEIL, Theresa. Padrões de design para aplicativos móveis. São Paulo: Novatec Editora, 2012. 208 p.

NIELSEN, J.; BUDIU, R. Mobile Usability. Berkley: New Riders, 2012. 216 p. ISBN 0321884485.

QUARESMA, M. Assessment of visual demand of typical data entry tasks in automotive navigation systems for iPhone. WORK: a Journal of Prevention, Assessment and Rehabilitation, Landsdale, v.41, p. 6139-6144, 2012.

QUARESMA, Manuela. Avaliação da usabilidade de sistemas de informação disponíveis em automóveis: umestudo ergonômico de sistemas de navegação GPS. Rio de Janeiro, 2010. 340p. Tese de Doutorado - Departamento de Artes e Design, Pontifícia Universidade Católica do Rio de Janeiro.

RESOLUÇÃO DO CONTRAN nº 242, de 22 de junho de 2007.

ROCHA, R.; VELOSO, M. Relatório Mobilize de inteligência de mercado - apps - \#5. Belo Horizonte, p.16 p. 2012

STEVENS, A.; QUIMBY, A.; BOARD, A.; KERSLOOT, T; BURNS, P. Design Guidelines for Safety of In-Vehicle Information Systems. Wokingham: TRL, 2002. 55p.

WROBLEWSKI, L. Mobile First. New York: A Book Apart, 2011. 123 p. ISBN 1937557022 .

\section{Agradecimentos}

Ao CNPq pela concessão da bolsa PIBIT (Programa Institucional de Bolsas de Iniciação em Desenvolvimento Tecnológico e Inovação) para o suporte na realização desta pesquisa. 
Recebido em: 05/06/2013

Aceito em: 01/10/2013

\section{Como citar}

QUARESMA, Manuela; GONÇALVES, Rafael Cirino. Análise da Usabilidade de aplicativos rede social para motoristas. Arcos Design. Rio de Janeiro: PPD ESDI - UERJ. Volume 7 Número 2 Dezembro 2013. pp. 25-52. Disponível em: [http://www.epublicacoes.uerj.br/index.php/arcosdesign]

\section{DOI}

10.12957/arcosdesign.2013.12180

\section{(c) (i) (2)}

A Revista Arcos Design está licenciada sob uma licença Creative Commons Atribuição - Não Comercial - Compartilha Igual 3.0 Não Adaptada. 